\title{
Recent Advances in Indirect Pulp Treatment Materials for Primary Teeth: A Literature Review
}

\author{
Afnan M Saber ${ }^{1}$, Omar A El Meligy², Sumer M Alaki ${ }^{3}$
}

\begin{abstract}
Aim: To provide an overview of the techniques of indirect pulp treatment (IPT) and the new materials used.

Background: Indirect Pulp Treatment (IPT) is a conservative treatment approach that can be used in primary molars. Pulpotomy has been adopted as the treatment of choice for deep caries in primary molars. IPT showed higher success rates in recent researches.

Materials and methods: Electronic search of English scientific papers was accomplished using PubMed, ScienceDirect, and Scopus. Papers published from 1995 to 2019 were included. Search terms used were recent advances, indirect pulp treatment, mineral trioxide aggregate (MTA), biodentine, TheraCal-LC, chlorhexidine gluconate (CHX), resin-modified glass ionomer (RMGI), and calcium hydroxide.

Review results: Seventy two papers were obtained from the electronic search and references of selected studies. Thirty five papers explained recent advances in IPT materials for primary molars. MTA produces more dentinal bridging with superior quality than calcium hydroxide. Similarly, Biodentine can form reparative dentin in a very short period. TheraCal-LC has increased stability and durability with strong physical properties and low solubility. Furthermore, $\mathrm{CHX}$ is a chemical disinfectant which can aid in increasing the success rate of IPT when conjugated with other materials. It produced highly successful IPT when combined with RMGI or calcium hydroxide.

Conclusion: IPT is the preferred treatment approach for preservation of primary dentition. CHX is an emerging material that can provide promising results in IPT when combined with other materials.

Clinical significance: Up to date, no material had replaced the popular use of calcium hydroxide in IPT. The use of CHX with RMGI can increase the success rate while preserving the advantages of the latter as it is considered the liner of choice for primary teeth, making IPT a suitable substitute for pulpotomy in primary molars.

Keywords: Biodentine, Chlorhexidine gluconate, MTA, Resin-modified glass ionomer, Review.

International Journal of Clinical Pediatric Dentistry (2021): 10.5005/jp-journals-10005-2073
\end{abstract}

\section{InTRODUCTION}

Decision for treating primary molars is challenging. Preservation of these teeth is essential to prevent premature loss and possible unfavorable outcomes on function and development. ${ }^{1}$ These include compromised occlusion and alignment, decrease in arch length, impaction, crowding, poor molar relationship, and ectopic eruption. ${ }^{2}$

In the past, pulpotomy was considered the best treatment approach for primary molars with deep carious lesions. This is because pulpotomy ensures removal of all involved tooth structure together with the infected part of the pulp leaving no areas of suspicious infection. ${ }^{3}$ Nowadays, indirect pulp treatment (IPT) has been established as a conservative alternative that can be used in primary molars with no pulpitis or with reversible pulpitis. ${ }^{3}$ IPT is a better substitute to pulpotomy as it permits normal exfoliation time through preserving pulp vitality.

Indirect pulp treatment includes removal of infected dental tissues, while allowing the affected tissues comprising hard dentine to be remineralized by a biocompatible material. ${ }^{1}$ This will stimulate the creation of tertiary dentin, avoiding pulp exposure, and consequently maintaining pulp vitality. ${ }^{1}$ Then, the cavity will be sealed by a restoration that inhibits microleakage. ${ }^{3}$

Moreover, proper selection of the case is essential to gain satisfactory results. Diagnosis relies on thorough dental history, clinical examination, and radiographic evaluation. ${ }^{4}$ In primary teeth, IPT presented success rate of $90 \%$ or greater regardless of the material used ${ }^{5}$
1,3 Department of Pediatric Dentistry, Faculty of Dentistry, King Abdulaziz University, Jeddah, Kingdom of Saudi Arabia

${ }^{2}$ Pediatric Dentistry Department, Faculty of Dentistry, King Abdulaziz University, Jeddah, Kingdom of Saudi Arabia; Pediatric Dentistry and Dental Public Health Department, Faculty of Dentistry, Alexandria University, Alexandria, Egypt

Corresponding Author: Omar A El Meligy, Department of Pediatric Dentistry, Faculty of Dentistry, King Abdulaziz University, Jeddah, Kingdom of Saudi Arabia; Pediatric Dentistry and Dental Public Health Department, Faculty of Dentistry, Alexandria University, Alexandria, Egypt, Phone: +966 557521584, e-mail: omeligy@kau.edu.sa

How to cite this article: Saber AM, El Meligy OA, Alaki SM. Recent Advances in Indirect Pulp Treatment Materials for Primary Teeth: A Literature Review. Int J Clin Pediatr Dent 2021;14(6):795-801.

Source of support: Nil

Conflict of interest: None

For many years, calcium hydroxide had been proposed to be the best material for IPT. ${ }^{6}$ This is due to its high ability to form tertiary dentine and consequently sealing the pulp with newly formed hard tissues. ${ }^{7}$ Nevertheless, calcium hydroxide has poor bonding ability to dentine and thus it is mechanically unstable. ${ }^{8}$ Moreover, calcium hydroxide may dissolve, therefore it is unable to avoid microleakage in the longer term. ${ }^{8}$ Furthermore, porosities might develop in the set material allowing leakage of microorganisms. ${ }^{8}$ Consequently, secondary infection will develop 
jeopardizing pulpal integrity. ${ }^{8}$ This raised the attention to locate materials with similar clinical performance while overcoming drawbacks of calcium hydroxide. ${ }^{9}$

Newly listed biocompatible materials that provided high success rates in IPT of primary molars include mineral trioxide aggregate (MTA), Biodentine, TheraCal-LC, and $2 \% \mathrm{CHX}$ with resinmodified glass ionomer (RMGI) or with calcium hydroxide. ${ }^{9-13}$

The purpose of this review was to provide an overview of the techniques of IPT and the new materials used.

\section{Materials and Methods}

Literature search of scientific papers was made electronically. Search engines used were PubMed, ScienceDirect, and Scopus. Papers published from 1995 to 2019 were included. Search terms used were recent advances, indirect pulp treatment, MTA, Biodentine, TheraCal-LC, CHX, resin-modified glass ionomer, and calcium hydroxide.

\section{Review Results}

Seventy two papers were obtained from the electronic search and references of selected studies. Thirty five papers discussed the recent advances in IPT materials for primary molars.

\section{Discussion}

\section{Definition}

Indirect pulp treatment is a form of vital pulp therapy that aims to preserve tooth vitality. ${ }^{3}$ In primary teeth, preservation of the pulp is of particular importance to allow for normal exfoliation time. ${ }^{1}$ In addition, premature loss of primary teeth can lead to unfavorable consequences including arch length discrepancies, malocclusion, and impaction. ${ }^{2}$

Moreover, in IPT, a layer of hard caries is left over the pulp to prevent pulpal exposure. ${ }^{14}$ However, deep carious lesions may cause bacterial infection in the coronal pulp altering pulpal integrity. ${ }^{15}$ Therefore, the selection of capping material is crucial. A biocompatible material with antibacterial effect should be used to create a suitable environment for pulpal healing. ${ }^{16}$

Additionally, the procedure of indirect pulp treatment comprises removal of soft dental tissues infected by caries while remineralizing the hard tissues affected by caries using a biocompatible material that encourages formation of tertiary dentin. ${ }^{1}$ Tertiary dentin is created via activation of adjacent odontoblasts. ${ }^{17}$ This will aid in avoiding pulp exposure and subsequently preserving pulp vitality. ${ }^{1}$

\section{Indications}

Indirect pulp treatment is indicated in primary teeth comprising deep caries with no pulpitis or with reversible pulpitis that are capable to heal following treatment. ${ }^{3}$

\section{Diagnosis}

Properly diagnosing teeth indicated for IPT is the key for success. ${ }^{18}$ Diagnosis starts by clinical examination to evaluate caries pattern. ${ }^{19}$ Additionally, radiographic examination is done to confirm caries depth and assess periapical and furcation areas. ${ }^{3}$ Moreover, cold test or electric pulp testing can be used to ascertain pulp vitality. ${ }^{19}$ Cold test is the suggested method that can be used in primary teeth. ${ }^{19}$ Nevertheless, electric pulp testing is not recommended as it is not reliable in primary teeth. ${ }^{20}$

\section{Technique}

Indirect pulp treatment is a risky procedure in which level of reduction should be carefully decided. A thin layer of caries is left to prevent pulpal exposure. ${ }^{14}$ Moreover, caries detecting tool can be used to aid in distinguishing infected from affected dentine and hence ensure adequate caries removal. ${ }^{21}$

The procedure starts using a high-speed handpiece to remove gross caries, followed by a low-speed handpiece with large round bur or a spoon excavator to remove residual caries close to the pulp. ${ }^{12}$ Later, a biocompatible material with antibacterial activity should be placed to ensure disinfection and healing of pulpal tissues. ${ }^{22}$ Finally, a well-sealed restoration should be placed to avoid microleakage. ${ }^{3}$

\section{Methods of Caries Detection}

Several methods have been suggested to distinguish infected from affected dentin. These include visual evaluation, tactile examination, caries detecting dye, laser light, electronic caries monitor, fiber-optic transillumination, and light scattering. ${ }^{23}$ Caries detecting dye is used frequently in researches and acts by staining collagen associated with organic matrix of less mineralized dentine, thus it is considered specific for demineralization. ${ }^{21}$

\section{Materials}

Several materials have been used in IPT. Selection of proper material may contribute to the success of IPT procedure. ${ }^{10}$ Material selected should provide adequate seal to the underlying dentin, preserve vitality of the pulp, and cause no post-treatment signs or symptoms. ${ }^{3}$ Different materials for IPT are illustrated in Table 1.

\section{Mineral Trioxide Aggregate}

Mineral trioxide aggregate (MTA) was first developed in 1993 by Mahmoud Torabinejad in Loma Linda University. ${ }^{24}$ In 1998, MTA was approved by The U.S. Food and Drug Administration. ${ }^{25}$ The early uses of MTA were sealing of root perforations or root-end filling. ${ }^{26}$ Later, MTA was broadly used in the field of pediatric dentistry.

Additionally, MTA is a Portland cement formed by the interaction of calcium oxide and silicon dioxide, resulting in the formation of tricalcium aluminate, tricalcium silicate, dicalcium silicate, and tetracalcium aluminoferrite. ${ }^{27}$ Bismuth oxide is then added to make the material easily distinguished on radiographs. ${ }^{27}$

There are two types of MTA: white MTA and gray MTA. ${ }^{28}$ The main difference between the two types is the concentration of ferrous oxide, magnesium oxide, and aluminium oxide. ${ }^{29}$ Additionally, the setting expansion of white MTA is lower than that of grey MTA. ${ }^{30}$

Moreover, MTA is a biocompatible material that is not mutagenic and less cytotoxic than other materials such as IRM and super EBA. ${ }^{31}$ When used in IPT, MTA can encourage collagen formation from cells, thus it is capable to form a dentine bridge with superior quality compared to calcium hydroxide. ${ }^{28}$ Also, MTA offers antibacterial activity against Streptococcus mutans (S. mutans), Streptococcus sanguis (S. sanguis) and Enterococcus faecalis (E. faecalis). ${ }^{22,33}$ However, no proved effect was detected of MTA against anaerobic bacteria, although some effect was noticed against facultative bacteria. ${ }^{27}$

On the contrary, the compressive strength of MTA is about 70 MPA, much lower than that of amalgam which is almost 
Table 1: Different materials used for indirect pulp treatment

\begin{tabular}{|c|c|c|c|}
\hline Material & Advantages & Disadvantages & Success rate \\
\hline $\begin{array}{l}\text { Mineral trioxide aggregate } \\
\text { (MTA) }\end{array}$ & $\begin{array}{l}\text {-Biocompatible } \\
\text {-Antimicrobial activity } \\
\text {-Increased marginal adaptation thus has } \\
\text { less leakage } \\
\text {-Improved sealing properties } \\
\text {-Induced osteogenesis } \\
\text {-Promotes healing }\end{array}$ & $\begin{array}{l}\text {-Discoloration }{ }^{68} \\
\text {-Prolonged setting time } \\
\text {-High cost }{ }^{25}\end{array}$ & $100 \%^{38}$ \\
\hline Biodentine & $\begin{array}{l}\text {-Biocompatible } \\
\text {-Antimicrobial activity } \\
\text {-Increased marginal adaptation } \\
\text {-High bond strength } \\
\text {-Can induce odontogenic differentiation } \\
\text { and formation of reparative dentin }\end{array}$ & - High cost ${ }^{70}$ & $98.3 \%^{49}$ \\
\hline TheraCal-LC & $\begin{array}{l}\text {-Enhanced physical properties } \\
\text {-Low solubility } \\
\text {-Improved sealing ability } \\
\text {-High calcium release } \\
\text {-Induced formation of dentin bridge }{ }^{11}\end{array}$ & -Opaque whitish color ${ }^{11}$ & $87.8 \%^{56}$ \\
\hline $\begin{array}{l}\text { Chlorhexidine gluconate } \\
\text { (CHX) } \\
\text { (In IPT, it was combined } \\
\text { with resin-modified glass } \\
\text { ionomer (RMGI) or calcium } \\
\text { hydroxide) }\end{array}$ & $\begin{array}{l}\text {-Disinfect any bacteria remains following } \\
\text { removal of infected dentin }{ }^{10}\end{array}$ & & $\begin{array}{l}\text { CHX with RMGI: } 97 \%{ }^{10} \\
\text { CHX with calcium hydrox- } \\
\text { ide: } 97 \%^{12}\end{array}$ \\
\hline $\begin{array}{l}\text { Resin-modified glass } \\
\text { ionomer (RMGI) }\end{array}$ & $\begin{array}{l}\text {-Biocompatible } \\
\text {-Antimicrobial activity } \\
\text {-Ability to bond to enamel and dentin } \\
\text {-High mechanical strength } \\
\text {-Uptake and releases fluoride }\end{array}$ & $\begin{array}{l}\text {-Cytotoxic effect } \\
\text {-Reduced wear resistance }\end{array}$ & $96.5 \%^{72}$ \\
\hline Calcium hydroxide & $\begin{array}{l}\text {-Biocompatible } \\
\text {-Antimicrobial activity } \\
\text {-Induction of calcified barrier } \\
\text {-Promotes healing and repair } \\
\text {-Stimulates fibroblasts } \\
\text {-Inexpensive } \\
\text {-Easy to use }\end{array}$ & $\begin{array}{l}\text {-May dissolve after one year } \\
\text {-Poor sealing properties }\end{array}$ & $94 \%{ }^{74}$ \\
\hline
\end{tabular}

311 MPA. ${ }^{34,35}$ Therefore, it is not recommended to use MTA in stress-bearing areas. ${ }^{36}$ Additionally, MTA has an excellent sealing ability, no solubility, and is more radiopaque on radiographs than calcium hydroxide. ${ }^{37}$

Several studies addressed the success of MTA used in IPT of primary molars. In 2015, George et al. published an article that evaluated 40 primary molars. They divided the sample into two groups: 20 teeth were treated with MTA while 20 teeth were treated with calcium hydroxide. ${ }^{9}$ They followed up the patients 6 months post treatment. ${ }^{9}$ They concluded that MTA is superior to calcium hydroxide in performing IPT of primary molars as it deposited more dentinal bridging. ${ }^{9}$

Moreover, a study was carried out in 2016 compared the success of IPT in primary molars performed with three materials: MTA, calcium hydroxide, and glass ionomer cement. ${ }^{38}$ The sample composed of 50 second primary molars distributed as follows: 18 teeth received IPT with MTA, 15 teeth received IPT with calcium hydroxide, whilst 17 teeth received IPT with glass ionomer cement. ${ }^{38}$ Teeth were followed up for 12 months. ${ }^{38}$ The conclusion was that there is no statistically significant difference in success rate among the three groups. ${ }^{38}$

In addition, another study was performed in 2016 compared IPT using MTA and TheraCal-LC in primary molars. ${ }^{39}$ Teeth treated with
MTA were 22 whilst teeth treated with TheraCal-LC were $21 .{ }^{39}$ No statistically significant difference was noticed between the two groups. ${ }^{39}$ Nevertheless, TheraCal-LC showed better handling properties. $^{39}$

Furthermore, a clinical trial was conducted evaluating the success of IPT performed with calcium hydroxide, MTA, and Biodentine in primary molars. ${ }^{40}$ The sample size was 45 primary molars divided into three groups in which 15 teeth were treated with each material. ${ }^{40}$ They found that the clinical success rate is $100 \%$ for all groups. ${ }^{40}$ However, Biodentine was superior to the other groups on radiographic evaluation. ${ }^{40}$ Nevertheless, High cost and extended setting time restricted the use of MTA in IPT. ${ }^{25,41}$

\section{Biodentine}

Biodentine is a new material that was introduced to replace dentine. ${ }^{42}$ It has mechanical properties similar to that of natural dentine. ${ }^{11}$ Biodentine is provided in a capsule that consists of the ideal liquid and powder ratio. ${ }^{43}$ Also, components of Biodentine include tricalcium silicate, dicalcium silicate, calcium carbonate, zirconium oxide, iron oxide, and calcium chloride. ${ }^{43}$

Moreover, Biodentine is a biocompatible material which stimulates tertiary dentine formation by encouraging odontoblastic differentiation. ${ }^{44}$ Odontoblastic differentiation takes place in 
a very short period, thus Biodentin is considered suitable for IPT. ${ }^{45}$ Additionally, Biodentine has strong antibacterial effects against S. mutans and E. faecalis. ${ }^{33}$ Surprisingly, Biodentine has greater zone of inhibition against $E$. faecalis and $S$. mutans when compared to MTA. ${ }^{33}$

Furthermore, the compressive strength of Biodentine can reach 300 MPA following first month of administration. ${ }^{46}$ This value is much higher than that of MTA though comparable to that of natural dentine, which is almost 297 MPA. ${ }^{34,35,47}$ Besides, Biodentine has good adaptability and seal, low solubility, and lower radiopacity when compared with MTA. ${ }^{48}$

In 2017, Pediatric Dentistry Journal published an article studying the effect of using Biodentine in IPT of primary molars. ${ }^{49}$ They evaluated 60 patients in which each had two teeth treated in a split-mouth design: one side underwent IPT with Biodentine and the other side treated with calcium hydroxide. ${ }^{49}$ They concluded that, after 12 months follow-up, there was no statistically significant difference in success rate among the two groups. ${ }^{49}$ Remarkably, the cost of Biodentine is reduced compared to MTA, which made it more accessible for use. ${ }^{43}$

\section{TheraCal-LC}

TheraCal-LC is a new light-cured resin-modified calcium silicate-filled base/ liner that is suggested for direct and indirect pulp treatments. ${ }^{11}$ TheraCal-LC consists of Portland cement, polyethylene glycol dimethacrylate polymerizable methacrylate monomers, and barium zirconate. ${ }^{50}$

Moreover, TheraCal-LC has high ability to release calcium. ${ }^{51}$ Calcium ions trigger proliferation and differentiation of pulpal tissues and stimulate hard tissue formation..$^{52}$ In addition, TheraCal-LC has improved physical properties, enhanced durability, increased stability, and reduced solubility. ${ }^{53}$

Regarding antibacterial activity, it was found that TheraCal-LC is as effective against S. mutans as calcium hydroxide. ${ }^{54}$ However, it has lower effect on S. sanguis and S. salivarius. ${ }^{54}$ Surprisingly, the compressive strength of TheraCal-LC is considered the greatest among MTA and biodentine. ${ }^{55}$ Neverthless, TheraCal-LC is opaque whitish in color. ${ }^{11}$ Therefore, it should be applied in a thin layer to avoid affecting the shade of final restoration. ${ }^{11}$

Furthermore, a study published in 2019 compared the success of IPT performed with TheraCal-LC, MTA, and calcium hydroxide. ${ }^{56}$ The sample composed of 153 second primary molars followed up for 24 months. ${ }^{56}$ They found no statistically significant difference in success rate of IPT among the three groups, although MTA group presented higher success rate. ${ }^{56}$

\section{Chlorhexidine Gluconate with Resin-modified Glass lonomer or with Calcium Hydroxide}

$\mathrm{CHX}$ is a chemical disinfectant which was proved to be effective in various dental uses. ${ }^{57} \mathrm{CHX}$ is the salt form of chlorhexidine, created via addition of gulonic acid. ${ }^{58}$

In addition, $\mathrm{CHX}$ is a strong bacteriostatic and bactericidal against multiple gram-positive and gram-negative organisms. ${ }^{10}$ These include E. faecalis, S. mutans, S. aureus, P. intermedia, C. albicans, viruses, and spores. ${ }^{59}$ Moreover, $\mathrm{CHX}$ is positively charged, therefor it acts by interrupting the osmolarity of bacterial cell wall, leading to cell death. ${ }^{60}$

Previously, CHX was used as a dental mouthwash, included in dentifrices, varnishes, gels, or used as intracanal medicament. ${ }^{61}$ Recently, CHX was used in IPT of primary molars in conjunction with other materials to offer antibacterial activity. ${ }^{10,12,13}$
Furthermore, some researches were carried out evaluating the effect of combining 2\% CHX with RMGI to perform IPT in primary molars. ${ }^{10,12,13}$ Although previous researches showed satisfactory results upon using RMGI alone in IPT, the aim of incorporating $2 \%$ $\mathrm{CHX}$ was to achieve a higher level of disinfection. ${ }^{10}$ The use of $\mathrm{CHX}$ with RMGI can maximize the success rate while preserving the advantages of the latter as it is considered the liner of choice for primary teeth. $^{10}$

The American Academy of Pediatric Dentistry published an article that studied the success of IPT performed using $2 \% \mathrm{CHX}$ together with RMGI in primary molars. ${ }^{10}$ Their goal of disinfection was to sterilize any residual bacteria after removal of infected dentine. ${ }^{10}$ Their results showed that using $2 \% \mathrm{CHX}$ with RMGI may contribute to the success of IPT. ${ }^{10}$

Additionally, a study was carried out in 2016 compared the effect of using $2 \%$ CHX with RMGl (as study group) vs. using $2 \%$ $\mathrm{CHX}$ with calcium hydroxide (as control group) in performing IPT of primary molars. ${ }^{12}$ The total sample size was 60 primary molars assigned randomly into study and control groups. They found that IPT with $2 \% \mathrm{CHX}$ and $\mathrm{RMGI}$ is recommended over the other group. $^{12}$

Recently, a study was conducted comparing three treatment groups in which IPT was performed by three different materials. ${ }^{13}$ The first group was treated with biodentine. The second group was treated with $2 \% \mathrm{CHX}$ followed by RMGI. The third group was treated using calcium hydroxide. The total sample size composed of 54 primary molars assigned randomly into the treatment groups. They found no statically significant difference among the three groups, although higher success rate was observed with biodentine. $^{13}$

\section{Restoration of Teeth Treated with Indirect Pulp Treatment}

Resin-based Composites

The use of resin-based composites allows minimal reduction of tooth structure. ${ }^{62}$ No extension for prevention is needed, minimal removal of involved tooth structure is sufficient. ${ }^{62}$ However, long time is needed for placement of resin restorations. ${ }^{62}$ Moreover, resins are technique sensitive, thus if the isolation is questionable, other type of restoration should be considered. ${ }^{62}$

\section{Stainless Steel Crowns}

Stainless steel crowns (SSCs) are considered the material of choice for primary molars with deep or extensive carious lesions. ${ }^{62}$ The use of SSCs raised over the past years as they have higher success rates than multisurface intracoronal restorations. ${ }^{62}$ Also, SSCs are durable, easily adapted, inexpensive, minimally technique sensitive, and allow for full coverage of the crown. ${ }^{63}$ Therefore, teeth treated with SSCs most likely will not require any further treatment in the future. ${ }^{62}$

\section{Success of Indirect Pulp Treatment over Pulpotomy}

AAPD recommended IPT as the preferred treatment for deep caries in primary teeth due to its higher success rate compared to pulpotomy and ability to provide normal exfoliation time. ${ }^{3}$

In 2000, Farooq et al. studied the success of IPT in comparison to formocresol pulpotomy (FP). Their results showed that IPT is significantly more successful than FP. Moreover, they stated that IPT can be successfully performed in a one-step procedure. ${ }^{14}$ 
In addition, a study was published in 2004 evaluating success rates of vital pulp therapies. They concluded that IPT produces superior long-term success compared to FP. Furthermore, teeth treated with FP experienced significantly earlier exfoliation pattern. ${ }^{64}$

On the other hand, a study conducted in 2015 compared IPT with MTA pulpotomy. They found no statistically significant difference in success rates between the two treatments. Additionally, indication for treatment are the same for the two procedures. Since IPT is less invasive, it is preferable over MTA pulpotomy. Other advantages of IPT include lesser side effects, lesser chair time, reduced cost, and finally is more acceptable by children. ${ }^{18}$

In 2016, pediatric dentistry journal published an article studied the success of IPT, FP, and ferric sulfate pulpotomy. They concluded that, over 4 years of follow - up, IPT produced better survival rate than either groups. ${ }^{65}$

Moreover, comparison between IPT and ferric sulfate pulpotomy was assessed in 2019. The study found that, over 4 years of follow-up, IPT produced significantly higher success rate than ferric sulfate pulpotomy. Additionally, teeth treated with ferric sulfate pulpotomy experienced accelerated exfoliation time. ${ }^{66}$

Finally, proper diagnosis is the key for a successful IPT. ${ }^{18}$ Besides, adequate caries excavation with complete cleaning of lateral walls plays a major role in the success of IPT. ${ }^{18}$

\section{ConcLusion}

AAPD recommended IPT as the preferred treatment approach for deep caries in primary teeth. This is due to its higher success rate compared to pulpotomy and ability to allow normal exfoliation time. Studies are carried out to find materials that can overcome drawbacks of calcium hydroxide. MTA produces more dentinal bridging with superior quality than calcium hydroxide. Similarly, Biodentine can form reparative dentin in a very short period. On the other hand, TheraCal-LC has increased stability and durability with strong physical properties and low solubility.

Furthermore, $\mathrm{CHX}$ is an emerging material that can provide promising results in IPT when conjugated with other materials such as RMGI and calcium hydroxide. Finally, proper diagnosis is the key for a successful IPT.

\section{Authors Contributions}

Literature search and studies selection were performed by Afnan $\mathrm{M}$. Saber, Omar A El Meligy, Sumer M Alaki; Afnan M Saber: provided the research idea and wrote the manuscript. Omar A El Meligy: contributed in the design and revised the manuscript. Sumer $M$ Alaki: performed contributions to manuscript revisions. All authors have read and approved the final manuscript.

\section{Clinical Significance}

Up to date, no material had replaced the popular use of calcium hydroxide in IPT. The use of $\mathrm{CHX}$ with RMGI can increase the success rate while preserving the advantages of the latter as it is considered the liner of choice for primary teeth, making IPT a suitable substitute for pulpotomy in primary molars.

\section{References}

1. Seale N. Indirect pulp therapy: an alternative to pulpotomy in primary teeth. Tex Dent J 2010;127(11):1175-1183.

2. Law C. Management of premature primary tooth loss in the child patient. J Calif Dent Assoc 2013;41(8):612-618.
3. AAPD. Guideline on pulp therapy for primary and immature permanent teeth. Pediatr Dent 2019;40(6):343-351.

4. Seale N, Coll J. Vital pulp therapy for primary dentition. Gen Dent 2010;58(3):194-200.

5. Coll JA. Indirect pulp capping and primary teeth: is the primary tooth pulpotomy out of date? J Endod 2008;34(7 Suppl):S34-S39. DOI: 10.1016/j.joen.2008.02.033

6. Pathak $S$, Bansode $P$, Wavdhane $M$, et al. Advances in pulp capping materials: a review. IOSR-JDMS 2017;16(2):31-37. DOI: 10.9790/0853-1602073137

7. Monea M, Mihai $P$, Stoica A, et al. Histologic evaluation of tertiary dentine after indirect pulp capping procedures. Key Eng Mater 2016;695:260-263. DOI: 10.4028/www.scientific. net/kem.695.260

8. Milosevic A. Calcium hydroxide in restorative dentistry. J Dent 1991;19(1):3-13. DOI: 10.1016/0300-5712(91)90028-W

9. George V, Janardhanan S, Varma B, et al. Clinical and radiographic evaluation of indirect pulp treatment with MTA and calcium hydroxide in primary teeth (in-vivo study). J Indian Soc Pedod Prev Dent 2015;33(2):104-110. DOI: 10.4103/0970-4388.155118

10. Rosenberg L, Atar M, Daronch M, et al. Prospective study of indirect pulp treatment in primary molars using resin-modified glass ionomer and $2 \%$ chlorhexidine gluconate: a 12 -month follow-up. Pediatr Dent 2013;35(1):13-17.

11. Singhal M, Chaudhary C, Anand R, Singh N, Sahni T. Recent advancements of indirect pulp capping in primary teeth: a review. J Adv Med Dent Scie Res 2015;3(5):S78-S82.

12. Venkatesh Babu N, Kavyashree B, Amitha H. Comparative assessment of success rate of indirect pulp treatment with $2 \%$ chlorhexidine gluconate disinfecting solution, calcium hydroxide and resin modified glass ionomer liner in primary teeth - A Prospective Study. IOSR-JDMS 2016;15(2):45-53. DOI: 10.9790/0853-15234553

13. Boddeda K, Rani C, V Vanga N,et al. Comparative evaluation of biodentine, $2 \%$ chlorhexidine with RMGIC and calcium hydroxide as indirect pulp capping materials in primary molars: an in vivo study. J Indian Soc Pedod Prev Dent 2019;37(1):60-66. DOI: 10.4103/jisppd.jisppd_213_17

14. Farooq N, Coll J, Kuwabara A, et al. Success rates of formocresol pulpotomy and indirect pulp therapy in the treatment of deep dentinal caries in primary teeth. Pediatr Dent 2000;22(4):278-286.

15. Reeves $\mathrm{R}$, Stanley $\mathrm{H}$. The relationship of bacterial penetration and pulpal pathosis in carious teeth. Oral Surg Oral Med Oral Pathol 1966;22(1):59-65. DOI: 10.1016/0030-4220(66)90143-5

16. Büyükgüral B, Cehreli Z. Effect of different adhesive protocols vs calcium hydroxide on primary tooth pulp with different remaining dentin thicknesses: 24 month results. Clin Oral Investig 2008;12(1):91-96. DOI: 10.1007/s00784-007-0152-x

17. Fuks A. Vital pulp therapy with new materials for primary teeth: new directions and treatment perspectives. J Endod 2008;34(7 Suppl):S18-S24. DOI: 10.1016/j.joen.2008.02.031

18. Vidya K, Patil S, Anegundi R. Is pulpotomy obsolete? A clinical study on the success rates of indirect pulp capping and pulpotomy in the treatment of deep dentinal caries in primary second molars. J Int Clin Dent Res Organ 2015;7(1):24-29. DOI: 10.4103/2231-0754.153491

19. Gopakumar R, Gopakumar M. Diagnostic aids in pediatric dentistry. Int J Clin Pediatr Dent 2011;4(1):1-7. DOI: 10.5005/jp-journals-10005-1073

20. Olgart L, Gazelius B, Lindh-Stromberg U. Laser Doppler flowmetry in assessing vitality in luxated permanent teeth. Int Endod J 1988;21(5):300-306. DOI: 10.1111/j.1365-2591.1988.tb01139.x

21. McComb D. Caries-detector dyes--how accurate and useful are they? J Can Dent Assoc 2000;66(4):195-198.

22. Duque C, Negrini Tde C, Hebling J, Spolidorio D. Inhibitory activity of glass-ionomer cements on cariogenic bacteria. Oper Dent 2005;30(5):636-640.

23. Peskersoy C, Turkun M, Onal B. Comparative clinical evaluation of the efficacy of a new method for caries diagnosis and excavation. J Conserv Dent 2015;18(5):364-368. DOI: 10.4103/0972-0707.164032 
24. Lee $S$, Monsef $M$, Torabinejad M. Sealing ability of a mineral trioxide aggregate for repair of lateral root perforations. J Endod 1993;19(11):541-544. DOI: 10.1016/S0099-2399(06)81282-3

25. Srinivasan V, Waterhouse $P$, Whitworth J. Mineral trioxide aggregate in paediatric dentistry. Int J Paediatr Dent 2009;19(1):34-47. DOI: 10.1111/j.1365-263X.2008.00959.x

26. Nandini S, Ballal S, Kandaswamy D. Influence of glass lonomer cement on the interface and setting reaction of mineral trioxide aggregate when used as a furcal repair material using laser Raman spectroscopic analysis. J Endod2007;33(2):167-172.

27. Torabinejad $M$, Hong $C$, Pitt Ford $T$, et al. Antibacterial effects of some root end filling materials. J Endod1995;21(8):403-406. DOI: 10.1016/s0099-2399(06)80824-1

28. Macwan C, Deshpande A. Mineral trioxide aggregate (MTA) in dentistry: a review of literature. J Oral Res Rev 2014;6(2):71-74. DOI: 10.4103/2249-4987.152914

29. Asgary S, Parirokh M, Egbbal M, et al. Chemical differences between white and gray mineral trioxide aggregate. J Endod2005; 31(2):101-103. DOI: 10.1097/01.don.0000133156.85164.b2

30. Storm B, Eichmiller F, Tordik P, et al. Setting expansion of gray and white mineral trioxide aggregate and Portland cement. J Endod2008;34(1):80-82. DOI: 10.1016/j.joen.2007.10.006

31. Sumer M, Muglali M, Bodrumlu E, et al. Reactions of connective tissue to amalgam, intermediate restorative material, mineral trioxide aggregate mixed with chlorhexidine. J Endod2006; 32(11):1094-1096. DOI: 10.1016/j.joen.2006.05.012

32. Al-Hezaimi K, Al-Shalan TA, Naghshbandi J, et al. Antibacterial effect of two mineral trioxide aggregate (MTA) preparations against Enterococcus faecalis and Streptococcus sanguis in vitro. J Endod 2006;32(11):1053-1056. DOI: 10.1016/j.joen.2006.06.004

33. Jain A, Gupta A, Agarwal R. Comparative evaluation of the antibacterial activity of two Biocompatible materials i.e. Biodentine and MTA when used as a direct pulp capping agent against streptococcus mutans and Enterococcus faecalis- an in vitro study. Endodontology 2018;30(1):66-68. DOI: 10.4103/ endo.endo_66_17

34. Torabinejad $M$, Chivian N. Clinical applications of mineral trioxide aggregate. J Endod1999;25(3):197-205. DOI: 10.1016/S0099-2399(99)80142-3

35. Schmitt D, Lee J, Bogen G. Multifaceted use of ProRoot MTA root canal repair material. Pediatr Dent 2001;23(4):326-330.

36. Malhotra N, Agarwal A, Mala K. Mineral Trioxide Aggregate: A Review of Physical Properties. Compend Contin Educ Dent 2013;34(2):e25-e32.

37. Luczaj-CepowiczE, Marczuk-Kolada G, Pawińska M, etal. Comparison of the radiopacity of selected materials used for vital pulp therapy: An in vitro assessment. Dent Med Probl 2019;56(3):285-290. DOI: $10.17219 / \mathrm{dmp} / 109550$

38. Mathur V, Dhillon J, Logani A, et al. Evaluation of indirect pulp capping using three different materials: a randomized control trial using cone-beam computed tomography. Indian J Dent Res 2016;27(6):623-629. DOI: 10.4103/0970-9290.199588

39. Menon N, Varma B, Janardhanan S, et al. Clinical and radiographic comparison of indirect pulp treatment using light-cured calcium silicate and mineral trioxide aggregate in primary molars: a randomized clinical trial. Contemp Clin Dent 2016;7(4):475-480. DOI: 10.4103/0976-237X.194109

40. Chauhan A, Dua P, Saini S, et al. In vivo outcomes of indirect pulp treatment in primary posterior teeth: 6 months' follow-up. Contemp Clin Dent 2018;9(Suppl 1):S69-S73. DOI: 10.4103/ccd.ccd_48_18

41. Torabinejad M, Hong C, McDonald F, et al. Physical and chemical properties of a new root-end filing material. J Endod1995;21(7):349-353. DOI: 10.1016/S0099-2399(06)80967-2

42. Arora V, Nikhil V, Sharma N, et al. Bioactive dentin replacement. IOSR-JDMS 2013;12(4):51-57. DOI: 10.9790/0853-1245157

43. Kaur M, Singh H, Dhillon J, et al. MTA versus Biodentine: Review of literature with a comparative analysis. J Clin Diagn Res 2017;11(8):ZG01-ZG05. DOI: 10.7860/JCDR/2017/25840.10374

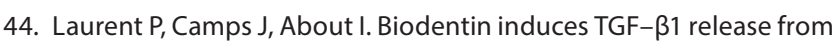
human pulp cells and early dental pulp mineralization. Int Endod J 2012;45(5):439-448. DOI: 10.1111/j.1365-2591.2011.01995.x

45. Kim J, Song Y, Min K, et al. Evaluation of reparative dentin formation of ProRoot MTA, biodentine and bio-aggregate using micro-CT and immunohistochemistry. Restor Dent Endod 2016;41(1):29-36. DOI: $10.5395 /$ rde.2016.41.1.29

46. Sarkar N, Caicedo R, Ritwik P, et al. Physiochemical basis of the biologic properties of mineral trioxide aggregate. J Endod2005;31(2): 97-100. DOI: 10.1097/01.don.0000133155.04468.41

47. Willems $G$, Lambrechts $P$, Braem M, et al. Composite resins in the 21st century. Quintessence Int 1993;24(9):641-658. DOI: $10.7860 / J C D R / 2014 / 7834.4174$

48. Ravichandra P, Vemisetty H, Deepthi K, et al. Comparative evaluation of marginal adaptation of biodentine and other commonly used root end filling materials - an in vitro study. J Clin Diagn Res 2014;8(3):243-245.

49. Garrocho-Rangel A, Quintana-Guevara K, Vázquez-Viera R, et al. Bioactive tricalcium silicate-based dentin substitute as an indirect pulp capping material for primary teeth: a 12-month follow-up. Pediatr Dent 2017;39(5):377-382.

50. Hebling J, Lessa F, Nogueira I, et al. Cytotoxicity of resin-based light-cured liners. Am J Dent 2009;22(3):137-142.

51. Gandolfi M, Siboni F, Prati C. Chemical-physical properties of TheraCal, a novel light-curable MTA- like material for pulp capping. Int Endod J 2012;45(6):571-579. DOI: 10.1111/j.1365-2591.2012.02013.x

52. Dawood A, Parashos P, Wong R,et al. Calcium silicate-based cements: composition, properties, and clinical applications. J Investig Clin Dent 2017;8(2):1-15. DOI: 10.1111/jicd.12195

53. Qureshi A, Soujanya E, Nandakumar, et al. Recent advances in pulp capping materials - an Overview. J Clin Diagn Res 2014;8(1):316-321. DOI: 10.7860/JCDR/2014/7719.3980

54. PoggioC,ArciolaCR,BeltramiR,etal.Cytocompatibilityandantibacterial properties of capping materials. ScientificWorldJournal 2014:181945. DOI: 10.1155/2014/181945

55. Nielsen M, Casey J, VanderWeele R, et al. Mechanical properties of new dental pulp-capping materials. Gen Dent 2016;64(1):44-48. DOI: 10.23804/ejpd.2019.20.02.04

56. Gurcan A, Seymen F. Clinical and radiographic evaluation of indirect pulp capping with three different materials: a 2-year follow-up study. Eur J Paediatr Dent2019;20(2):105-110.

57. Leonardo M, Tanomaru Filho M, Silva L, et al. In vivo antimicrobial activity of $2 \%$ chlorhexidine used as a root canal irrigating solution. J Endod1999;25(3):167-171. DOI: 10.1016/s0099-2399(99)80135-6

58. Zeng $P$, Rao $A$, Wiedmann $T$, et al. Solubility properties of chlorhexidine salts. Drug Dev Ind Pharm 2009;35(2):172-176. DOI: $10.1080 / 03639040802220318$

59. Padiyar B, Marwah N, Gupta S, et al. Comparative evaluation of effects of triphala, garlic extracts, and chlorhexidine mouthwashes on salivary Streptococcus mutans counts and oral hygiene status. Int J Clin Pediatr Dent 2018;11(4):299-306. DOI: 10.5005/jp-journals-10005-1530

60. Markowska K, Anna M, Wolska G. Silver nanoparticles as an alternative strategy against bacterial biofilms- review. Acta Biochim Pol 2013;60(4):523-530.

61. Rôças IN, Siqueira JF Jr. Comparison of the in vivo antimicrobial effectiveness of sodium hypochlorite and chlorhexidine used as root canal irrigants: a molecular microbiology study. J Endod 2011;37(2):143-150. DOI: 10.1016/j.joen.2010.11.006

62. AAPD. Guideline on pediatric restorative dentistry. Pediatr Dent 2012;34(5):173-180.

63. Seale N. The use of stainless steel crowns. Pediatr Dent. 2002;24(5):501-505.

64. Vij R, Coll J, Shelton P, Farooq N. Caries control and other variables associated with success of primary molar vital pulp therapy. Pediatr Dent 2004;26(3):214-220.

65. Wunsch P, Kuhnen M, Best A, Brickhouse T. Retrospective study of the survival rates of indirect pulp therapy versus different pulpotomy medicaments. Pediatr Dent 2016;38(5):406-411. 
66. Fang R, Chang K, Lin Y. Comparison of long-term outcomes between ferric sulfate pulpotomy and indirect pulp therapy in primary molars. J Dent Sci 2019;14(2):134-137. DOI: 10.1016/j.jds.2019.03.008

67. Tawil P, Duggan D, Galicia J. Mineral trioxide aggregate (MTA): its history, composition, and clinical applications. Compend Contin Educ Dent 2015;36(4):247-252.

68. Bogen G, Kim J, Bakland L. Direct pulp capping with mineral trioxide aggregate: an observational study. J Am Dent Assoc 2008;139(3): 305-315. DOI: 10.14219/jada.archive.2008.0160

69. Torabinejad M, Hong C, McDonald F, et al. Physical and chemical properties of a new root-end Iling material. J Endod1995; 21(7):349-353. DOI: 10.1016/S0099-2399(06)80967-2

70. Priyalakshmi S, Ranjan M. Review on biodentine-a bioactive dentin substitute. IOSR-JDMS 2014;13(1):13-17. DOI: 10.9790/0853-13131317
71. Aranha A, Giro E, Souza P, et al. Effect of curing regime on the cytotoxicity of resin-modified glass-ionomer lining cements applied to an odonoblast-cell line. Dent Mater 2006; 22(9):864-869. DOI: 10.1016/j.dental.2005.11.015

72. Kotsanos N, Arizos S. Evaluation of a resin modified glass ionomer serving both as indirect pulp therapy and as restorative material for primary molars. Eur Arch Paediatr Dent 2011;12(3):170-175. DOI: 10.1007/BF03262801

73. Baranwal R, Singh BD, Dubey A, et al. Calcium hydroxide in dentistry. Chettinad Health City Medical Journal 2016;5(1):30-33.

74. Trairatvorakul C, Sastararuji T. Indirect pulp treatment vs antibiotic sterilization of deep caries in mandibular primary molars. Int J Paediatr Dent 2014;24(1):23-31. DOI: 10.1111/ipd.12022 